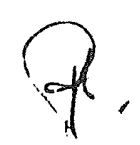

Reprint from

Ecological Studies. Analysis and Synthesis, Vol. 4

Edited by A. Hadas et al.

Springer-Verlag Berlin · Heidelberg · New York 1973

Printed in Germany. Not for Sale

Dynamics of Water in the Soil-Plant-Atmosphere System:

A Model Named Troika

J. R. LAMibert and F. W. T. PENNING de VRIES 
List of Internal Reports of Department of Theoretical Production Ecology:

No:

1 D. Barél, F. van Egmond, C. de Jonge, M.J.Frissel, M. Leistra, C.T. de Wit. 1969. Simulatie van de diffusie in lineaire, cylindrische en sferische systemen. Werkgroep: Simulatie van transport in grond en plant.

2 L. Evangelisti and R. van der Weert. 1971. A simulation model for transpiration of crops. 


\title{
Dynamics of Water in the Soil-Mlant-Amosphere System: A Model Named Troika
}

\author{
J.R. LAmbert and F. W. T. PEnNING DE VRIES
}

Water tends to move from the surrounding soil to root surfaces, through the plant and thence into the atmosphere along a gradient of water potential. The several rates are generally transient, and thus attempts to look at the processes from a viewpoint smaller than that of a system are furile. Water uptake rates depend on soil state and paramerric variables, such as water potential and conductivity, and on similar plant characteristics. The latter in turn depend on activities throughout the plant previous to the cime of rate calculations, including the history of transpiration and water uptake. Rates of movement within and from the plant depend on the environment as well as the physiological conditions of the plant.

No known model of a complete dynamic soil-plant-atmosphere system has been developed, probably mainly because of the difficulty in simulating the entire system and in testing the validity of the model. The preserited model is a computer model of such a system that allows manipulation of all parameters and environmental variables.

The dynamics of a simplified but complete soil-plant-atmosphere system are investigated by considering the flow of water from the cylinder of the soil surrounding a root system, the transpiration rates resulting from the environmental and physiological conditions, the water balance of a plant, and the heat balance of a leaf. The main restrictions of this model compared to reality are the assumptions that the modelled plant is not growing or aging and that it has a single, straight root. The flow from the soil to the atmosphere is treated in a unified manner so that boundary conditions at the soil-plant interface, i.e. the root, are a natural resultant of the analysis. Time variant environmental conditions are used.

The simulation model is programmed in $\$ / 360$ CSMP (IBM, 1968) a continuous system simulation language which combines semiparallel statement sequencing, complete FORTRAN capabiliries, use: oriented input and output, and centralized integration. An introduction to the language has been described by BRENNAN et al. (1970) using examples. The automatic sorting of the structure statements by the system largely relieves the modeller of the minutiae of programming and allows subprograms to be easily combined to yield programs describing either larger systems in the same detail or the same system in greater detail. Within the CSMP program subroutines were called to generate instructions for machine plotring. Fig. 4 through 9 are photographic reproductions of such plots.

The need for the model described herein was realized during attempts to simulate seasonal crop growth. Specifically, the model was developed to look in detail at the effect of soil moisture level and weather conditions on the course of plant water potential throughout the day, on recovery of the plant water potential at night, on development of water potential profiles around the roots throughout the day, and on redistribution of soil water during nighttime. 


\section{Previous Work}

KLUTE and PETERS (1969) have recently reviewed the analyses of flow of water to roots. The single-root models have all a) assumed cylindrical geometry in a soil homogeneous with depth, so that one-dimensional flow results, b) neglected graviry, and c) assumed constant diffusivity and/or steady-state flow. Analyrical solutions for unsteady flow of water from a finite cylinder assumed constant diffusivity (SHIH, 1969) or that diffusivity is an exponential function of moisture content (SINGH and FRANZINI, 1967). PHILIP (1957) and GARDNER (1960) assumed a constant flux into the root as a boundary condition to obtain water potentials in the root-soil system. The plant factors influencing the flow of water in plants have been discussed by COWAN and MILTHORPE (1968) and by SLATYer (1967). GARDNER (1965) and COWAN (1965) have attempted to model the soil and plant resistances to flow, but both of these models force a flux rate to exist, either across the root or leaf surface, and assume steady-state type water potentials in the soil.

\section{The Model}

A more realistic point of view of water transport models considers the flow of water as a dynamic, unsteady-state phenomenon reacting to any change in the soil-plantatmosphere system. The model described is a transient one in that all rates, e.g., flow rates, are computed from state variables, e.g., water contents; parameters, e.g., cuticular conductivity; and functions, e.g., radiation intensity as a function of time. These rates are realized in a parallel manner over a short time interval, changing the state variables. Rates are again computed, etc., until the required simulation time has elapsed. Thus dynamic interrelationships of all parts of the system are maintained.

This description of the model is necessarily brief; the detailed program with documentation is available (LAMBERT and PENNING DE. VRIES, 1971).

\section{Plant Segment}

The water balance of a transpiring plant together with the consequent physical and physiological changes in the plant serves to describe the dynamic plant response to its water regime, although many physical aspects of the environment, such as leat heat balance and photosynthesis, must also be considered.

The plant is assumed to consist of a horizontal leaf of specified area and mass together with a root system of specified length and mass. The rate of loss of water by transpiration and the rate of supply to the leaf alter the plant water content. The consequent hydration level determines the total leaf water potential and leaf pressure potential. A similar analysis occurs for the root system.

Carbon dioxide, heat and water balances in the leaf influence stomatal aperture, and thus transpiration rate, by action of both the guard and subsidiary cells. A first-order exponential delay of the movements of the guard cells also contributes to the timedependent behavior of the system. The carbon dioxide level within the leaf is determined by the incident light intensity and stomatal aperture. Cuticular conductivity is assumed to be constant at one-fifth the maximum stomatal conductivity.

The flow rate of water into the root is assumed to be equal to the difference between the water potential of the peel of soil immediately surrounding the root, supposed to be 
well filled with root hairs, and the root water potential, multiplied by a constant root permeability.

Flow from the root to the leaf is across a stem resistance, assumed to be from the root endodermis to the sub-stomatal cavity.

The more important physical plant parameters included in the model are root length. root diameter, area of the leaf, permeability of the root, diffusive resistances, and the fraction of incident short-wave radiation absorbed by the leaf. The more important physiological relationships are the effect of the pressure potential of the guard and subsidiary cells on stomatal aperture, the relationship between internal $\mathrm{CO}_{2}$ concentration and guard cell pressure potential, and the relationship between relative water content and pressure potential.

Time-variant short-wave radiation, air temperature, relative humidity, wind speed, and aerial carbon dioxide concentration are inputs to the model.

The plant segment of this model is more completely described by PENNING DE VRIES (1972).

\section{Soil Segment}

The soil surrounding the root is assumed to be homogeneous and non-hysteretic, and to occupy a cylinder concentric with the root axis. The cylinder is composed of annular cylinders or peels. The only soil boundary condition used is that no flow from outside the cylinder occurs, but any desired boundary condition might be imposed on the peels.

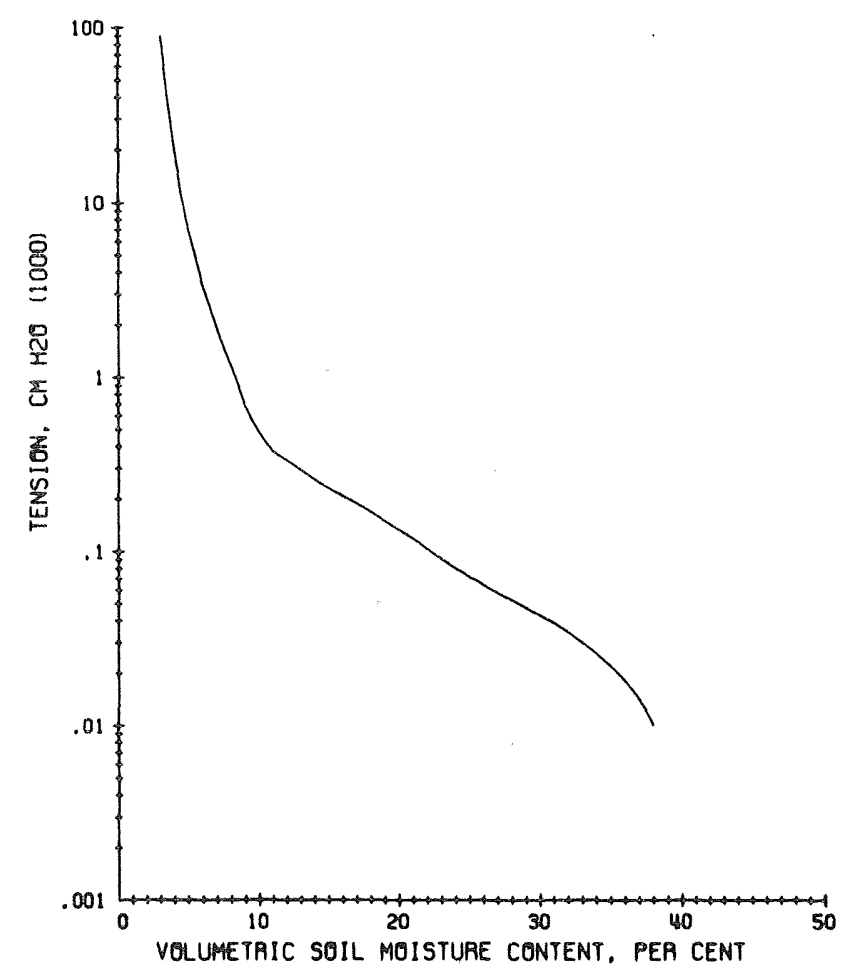

Fig. 1. Soil moisture characteristic, Sarpy Loam 
The rate of water flow from a peel to the adjacent one is due to the water potential difference between the two. Isothermal conditions are assumed, and osmotic and gravity potentials are neglected, so that water potential is equated to negative matric tension and only radial flow occurs. Preliminary investigations indicated that the effective conductivity between two peels could well be taken as the arithmetic average of the conductivities corresponding to the respective water potentials.

The soil portion of the model originated from a general model for one-dimensional, unsaturated flow in a non-hysteretic soil where isothermal conditions occur and osmotic potentials are neglected (KEULEN, 1971).

\section{Data}

A young, bean-like plant having a leaf area of $100 \mathrm{~cm}^{2}$, a leaf width of $10 \mathrm{~cm}$, a specific heat of $1 \mathrm{cal} / \mathrm{g} /{ }^{\circ} \mathrm{C}$, a thickness of $0.03 \mathrm{~cm}$, and a volumetric fraction of water when saturated of 0.90 was used as the above-ground plant. At the beginning of simulation, the leaf temperature was made equal to the air temperature and the leaf water potential made nearly equal to the soil water potential. It was assumed that 0.7 of the

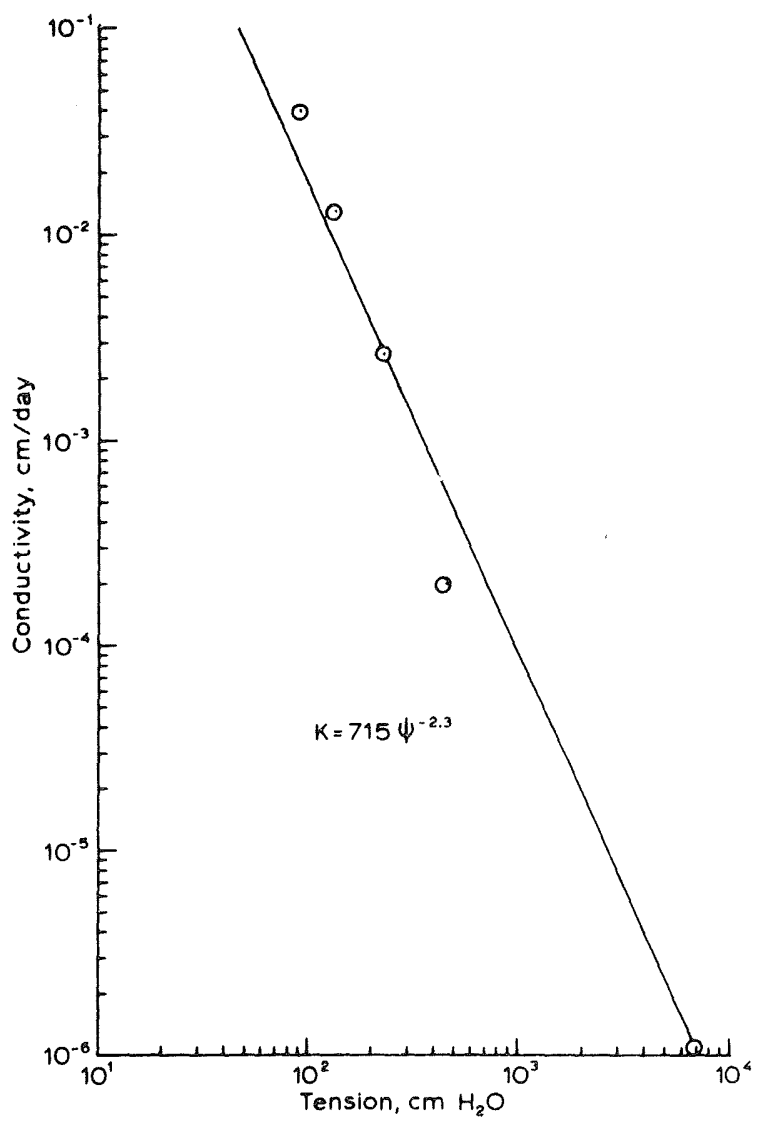

Fig. 2. Conductivity of Sarpy Loam 
incident short-wave radiation was absorbed. The root was assumed to be of $0.06 \mathrm{~cm}$ effective diameter and to occupy $1 \mathrm{~cm}^{3}$ of volume with a specific root length of $300 \mathrm{~cm} / \mathrm{cm}^{3}$. The permeability of the root was assumed to be $5 \times 10^{-6} \mathrm{~cm}^{3} / \mathrm{sec} / \mathrm{bar} / \mathrm{cm}^{2}$, and the stem resistance to be $500 \mathrm{bar} \mathrm{sec} / \mathrm{cm}^{3}$. The best estimates of various physiological parameters or data found in the literature were used.

The soil chosen was a Sarpy Loam as characterized by HANKS and BOWERS (1962). Moisture characteristic data were smoothed (Fig. 1) and the conductivity data (Fig. 2) were approximated by the equation

$$
\mathrm{K}=715 \psi^{-2.3}
$$

where $\mathrm{K}=$ conductivity in $\mathrm{cm} / \mathrm{day}$, and $\psi=$ soil moisture tension in $\mathrm{cm} \mathrm{H}_{2} \mathrm{O}$

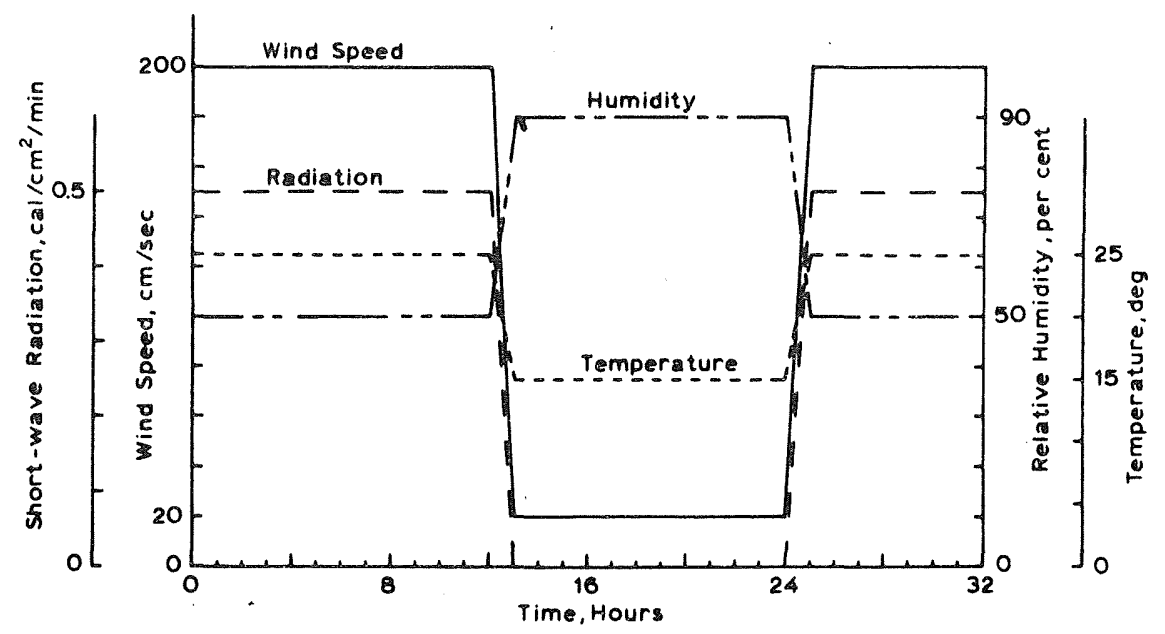

Fig. 3. Aerial environment used in simulation

Eleven cylindrical layers about the root, graduated in thickness from $0.06 \mathrm{~cm}$ in multiples of 1.2 , were used in the analysis so that the total cylinder was $1.96 \mathrm{~cm}$ in radius. This is somewhat larger than is found in the field but one major objective of the simulation was to evaluate just how large the cones of water potential depression are under certain conditions.

The plant was subjected to the environment diagrammed in Fig. 3. At the moment that the root water potential fell to -30 bars, time was instantaneously advanced to the onset of darkness so that the plant water potential would not become unreasonably low. Such an advance occurred only under the driest conditions, where time was advanced from 7.28 to 12 hours. All other simulation runs used the environment of Fig. 3 straight forward. The $\mathrm{CO}_{2}$ concentration was taken to be $300 \mathrm{ppm}$. Each run lasted for 24 hours of simulation time.

Six soil moisture levels between 0.25 and 10.0 bars soil moisture tension were used as initial conditions so that the response of the system over a range of soil moisture levels could be determined. 


\section{Results}

The simulated response of such a system must be evaluated logically since so few data are available for comparison.

The subjects investigated in more detail in the six runs are transpiration and water uptake by the plant during day and night and the total water potential of the leaf, root and soil peels in time. Leaf temperature and stomatal aperture were also studied.

Transpiration rates were considerably greater in daytime than at night, and greater under higher initial soil moisture conditions. Stomates closed at night and opened in the daytime with the aperture depending on soil moisture level and the dynamics of the system. Cones of water potential depression built up about the root with the dimensions depending on initial soil moisture level, soil and root characteristics, and time. At night, water tended to redistribute uniformly in the wetter soils, but at the lower soil moisture levels, 11 hours was not sufficient time for complete redistribution. Under higher initial soil moisture levels, considerably higher transpiration rates resulted than from lower levels, as can be seen from Table 1 .

Table 1. Model response to described specific conditions

\begin{tabular}{|c|c|c|c|c|c|c|}
\hline & \multicolumn{6}{|c|}{ Initial Soil Moisture Potential, $\left(10^{3}\right) \mathrm{cm} \mathrm{H}_{2} \mathrm{O}$} \\
\hline & -0.25 & -0.78 & $-1,46$ & -2.94 & -5.86 & $-10.2^{\mathrm{a}}$ \\
\hline $\begin{array}{l}\text { Transpired water, } \\
12 \mathrm{hrs} \text {. high sun, grams }\end{array}$ & 22.0 & 19.6 & 12.7 & 5.6 & 4.1 & 3.6 \\
\hline $\begin{array}{l}\text { Transpired water, } \\
13 \text { hrs. daylight }\end{array}$ & 22.9 & 20.4 & 13.2 & 5.8 & 4.2 & 3.9 \\
\hline Transpired water, 24 hours & 23.1 & 20.7 & 13.4 & 6.1 & 4.5 & 4.2 \\
\hline $\begin{array}{l}\text { Root water uptake, } \\
12 \text { hrs. high sun, grams } \\
\text { Root water uptake, }\end{array}$ & 21.9 & 19.5 & 12.4 & 5.3 & 2.4 & 1.0 \\
\hline 13 hrs. daylight & 22.9 & 20.4 & 13.1 & 5.6 & 2.6 & 1.2 \\
\hline Root water uptake, 24 hrs. & 23.0 & 20.6 & 13.5 & 6.1 & 4.0 & 2.0 \\
\hline $\begin{array}{l}\text { Maximum leaf temperature, }{ }^{\circ} \mathrm{C} \\
\text { Minimum leaf water potential, }\end{array}$ & 26.4 & 26.6 & 27.2 & 27.7 & 27.7 & 27.7 \\
\hline $\begin{array}{l}10^{3} \mathrm{~cm} \mathrm{H} \mathrm{H}_{2} \mathrm{O} \\
\text { Minimum root water potential, }\end{array}$ & -2.5 & -5.4 & -9.7 & -11.7 & -27.3 & $-33.1^{b}$ \\
\hline $10^{3} \mathrm{~cm} \mathrm{H}_{2} \mathrm{O}$ & -2.2 & -5.2 & -9.6 & -11.7 & -27.3 & $-33.1^{b}$ \\
\hline $\begin{array}{l}\text { Recovery leaf water potential, } \\
10^{3} \mathrm{~cm} \mathrm{H} \mathrm{H}_{2} \mathrm{O} \\
\text { Recovery root water potential, }\end{array}$ & -0.31 & -1.12 & -1.91 & -3.65 & -14.7 & -23.7 \\
\hline $\begin{array}{l}\quad 10^{3} \mathrm{~cm} \mathrm{H}_{2} \mathrm{O} \\
\text { Recovery water potential in }\end{array}$ & -0.27 & -1.14 & -1.88 & -3.68 & -14.7 & -23.6 \\
\hline outer soil layer, $10^{3} \mathrm{~cm} \mathrm{H}_{2} \mathrm{O}$ & -0.27 & -1.08 & -1.82 & -3.27 & -6.14 & -10.5 \\
\hline
\end{tabular}

anitial daylight lasted 7.3 hours

b During initial day

Essentially all of the transpiration and uptake occurred during daylight; except when the soil was initially dry. During nighttime the driving potential differences were much lower and the resistances higher since the stomates were closed. Under dry conditions water uptake by the root continued at similar rates at night, however, since the root and 
soil resistances were not directly affected, and the potential differences remained large while the system very slowly approached redistribution and equilibrium. The moist soil and plant very quickly regained complete redistribution with very little subsequent uptake.

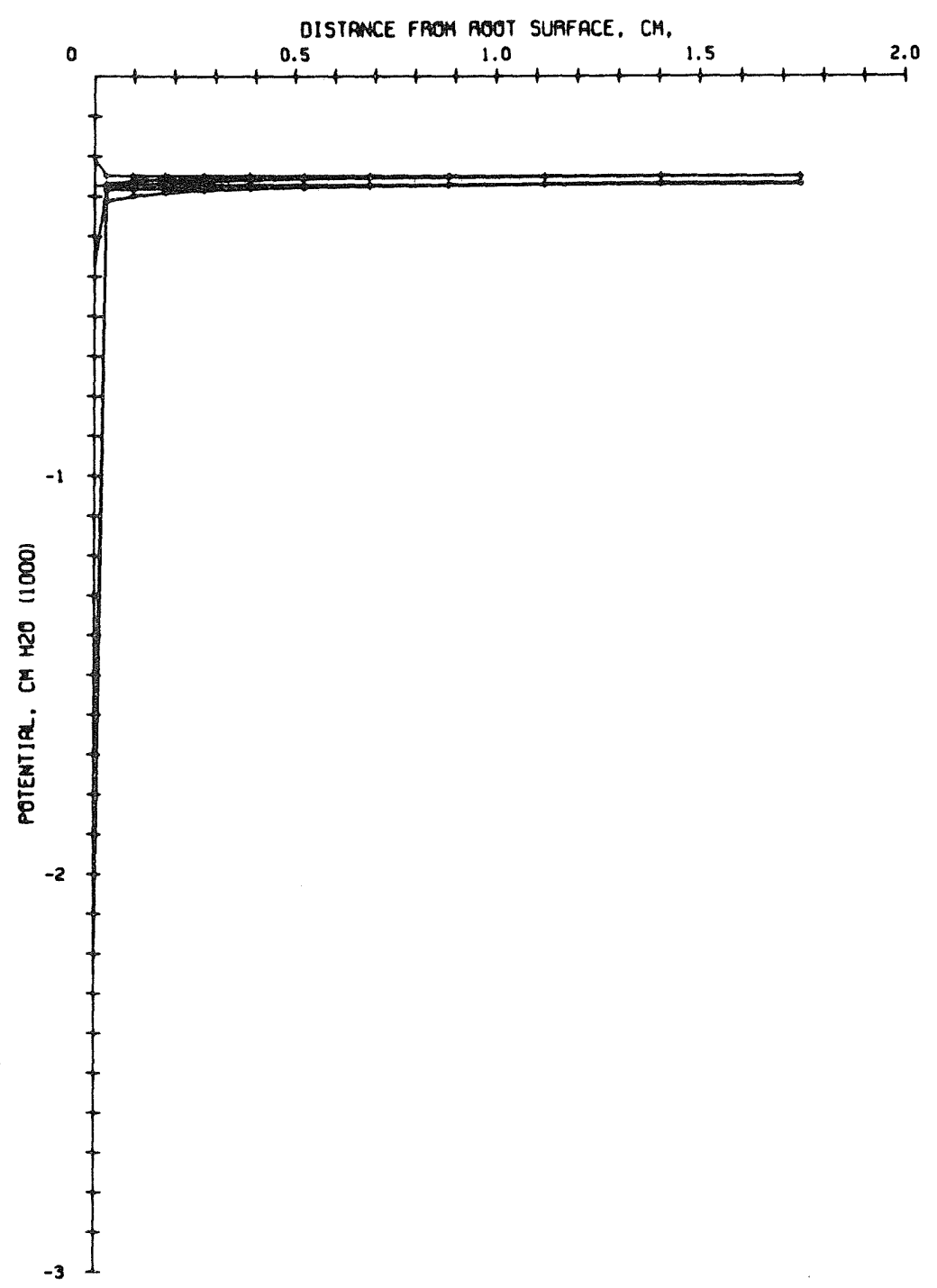

Fig. 4. Water potential distribution at $0,1,2,12,13$ and 15 hours, beginning at -0.25 bar initial condition

Little rise in leat temperature occurred even though a moderately high radiation level was impressed. It is clear that the latent heat of transpiration does aid in limiting leaf temperature. However, under the simulated conditions a maximum benefit of only 1.3 degrees between the lowest and highest transpiration rates occurred. This benefit would depend very strongly on wind speed in particular. 


\section{Soil Water Potentials}

On the $Y$-axis of Figs. 4 through 9 is plotted the root water potential, and at increasing radii the water potential of each layer is indicated by + . Initially the soil water content of all peels was equal. Using the initial condition of -0.25 bars, only the potential drop

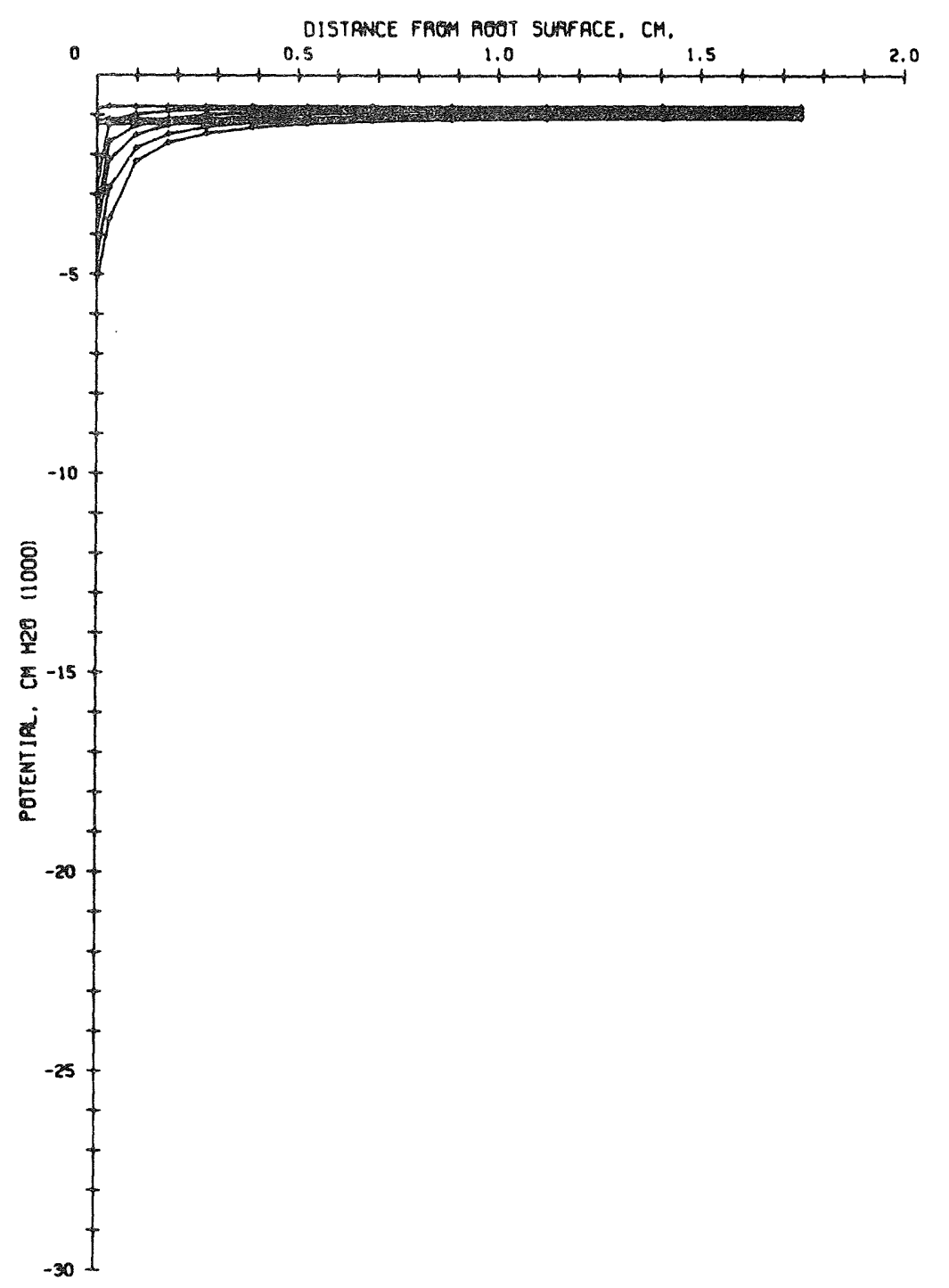

Fig. 5. Water potential distribution at $0,1,2,4,8,12,14$ and 24 hours, beginning at -0.77 bar initial condition

across the root was significant due to the high conductivity of the soil. Essentially complete redistribution occurred by 13 hours.

When the soil was initially at -0.77 bars, the soil conductivity was low enough that a 
cone of increasing depth and radius did develop (Fig. 5). The root water potential dropped to -5 bars and the potential drop across the root was still greater than that in the soil adjacent to the root. Redistribution was essentially complete after 14 hours.

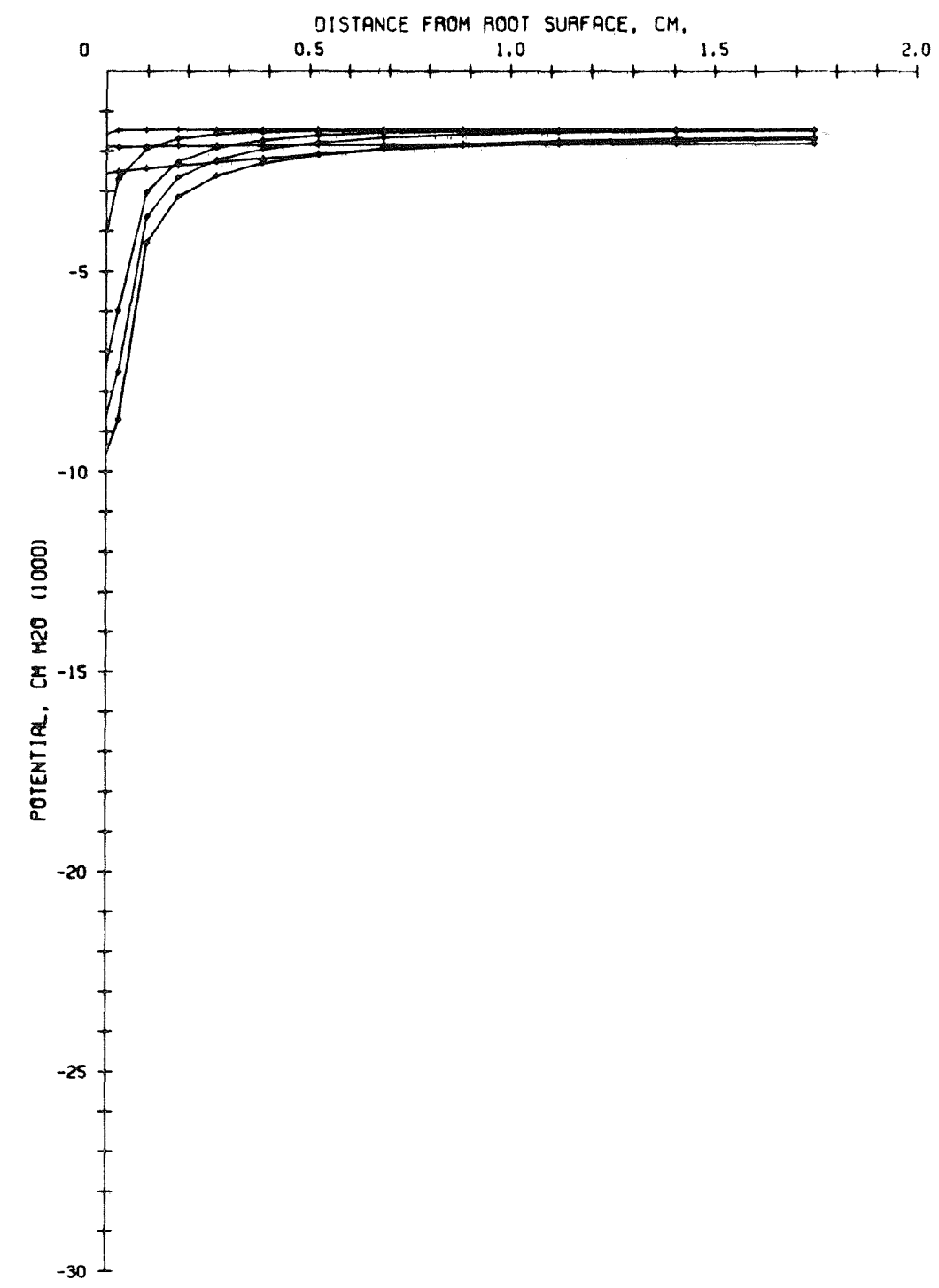

Fig. 6. Water potential distribution at $0,1,2,4,12,14$ and 24 hours, beginning at -1.44 bar initial condition

Under the initial condition of -1.44 bars, the potential drops across the root and in the soil adjacent to the root were of the same order of magnitude (Fig. 6).

The small potential drop across the root of Fig. 7 (initial condition of -2.89 bars) in relation to the potential drop in the soil is readily apparent. By examining the successive 
profiles at $12,14,16,24$ hours the slower redistribution of water compared with higher initial moisture levels can be seen.

The several profiles of Fig. 8 are somewhat difficult to follow but they are presented

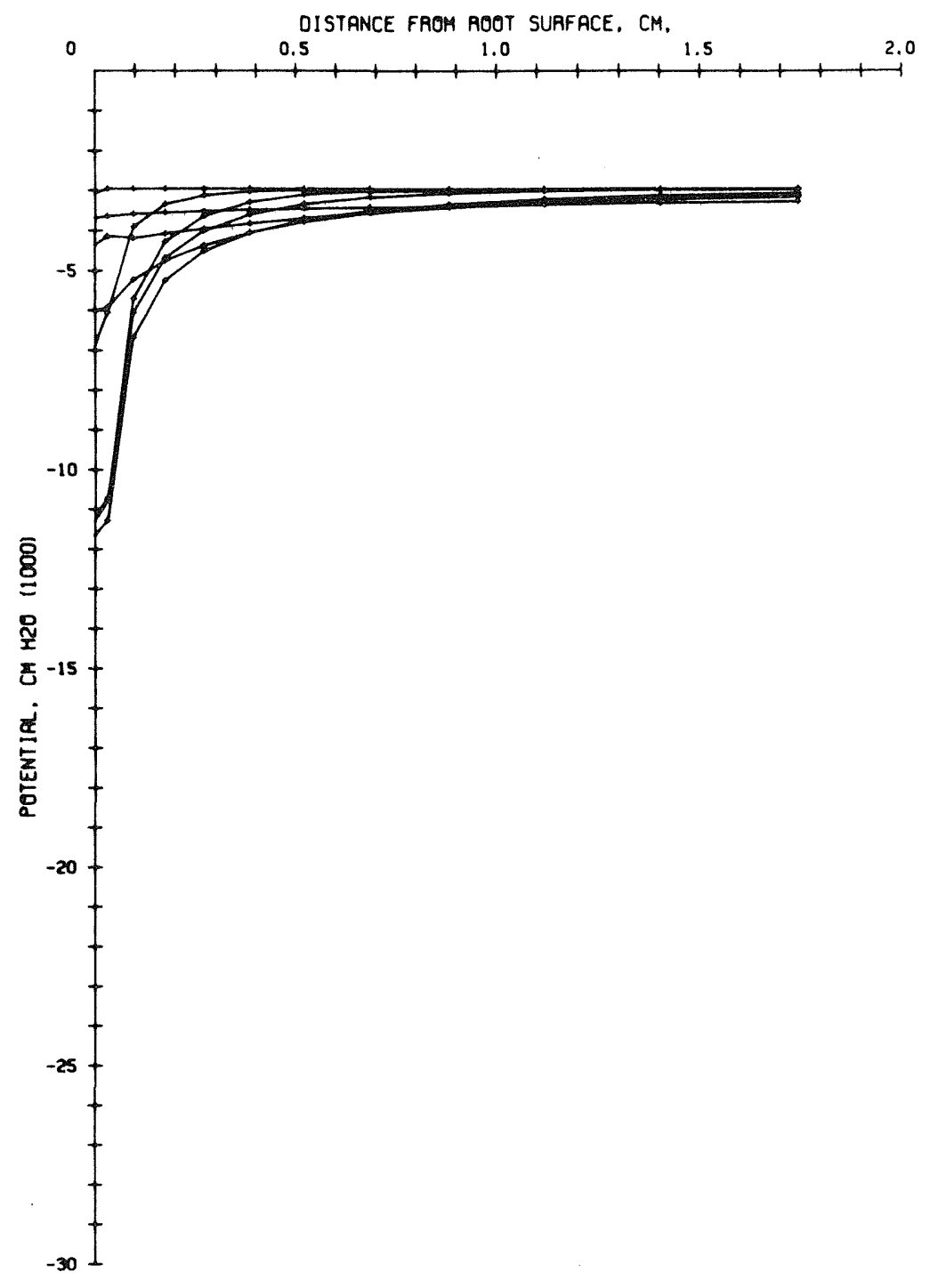

Fig. 7. Water potential distribution at $0,1,2,4,12,14,16$ and 24 hours, beginning at -2.89 bar initial condition

so that rather slow recovery can be seen. After 24 hours the profile beginning at a root water potential of -14.4 bars had resulted,

The dry extreme represented by Fig. 9 (initial condition of -10.2 bars) indicates the significantly higher potential drop in the soil compared with that across the root. A 
rather deep cone of profile depression developed rather quickly due to the low soil conductivity and the apex of the cone at the root water potential continued to drop throughout the day. Extremely slow recovery of the profile occurred. At the outer limit of the soil cylinder relatively little drop in potential occurred during the 18 hours simulated.

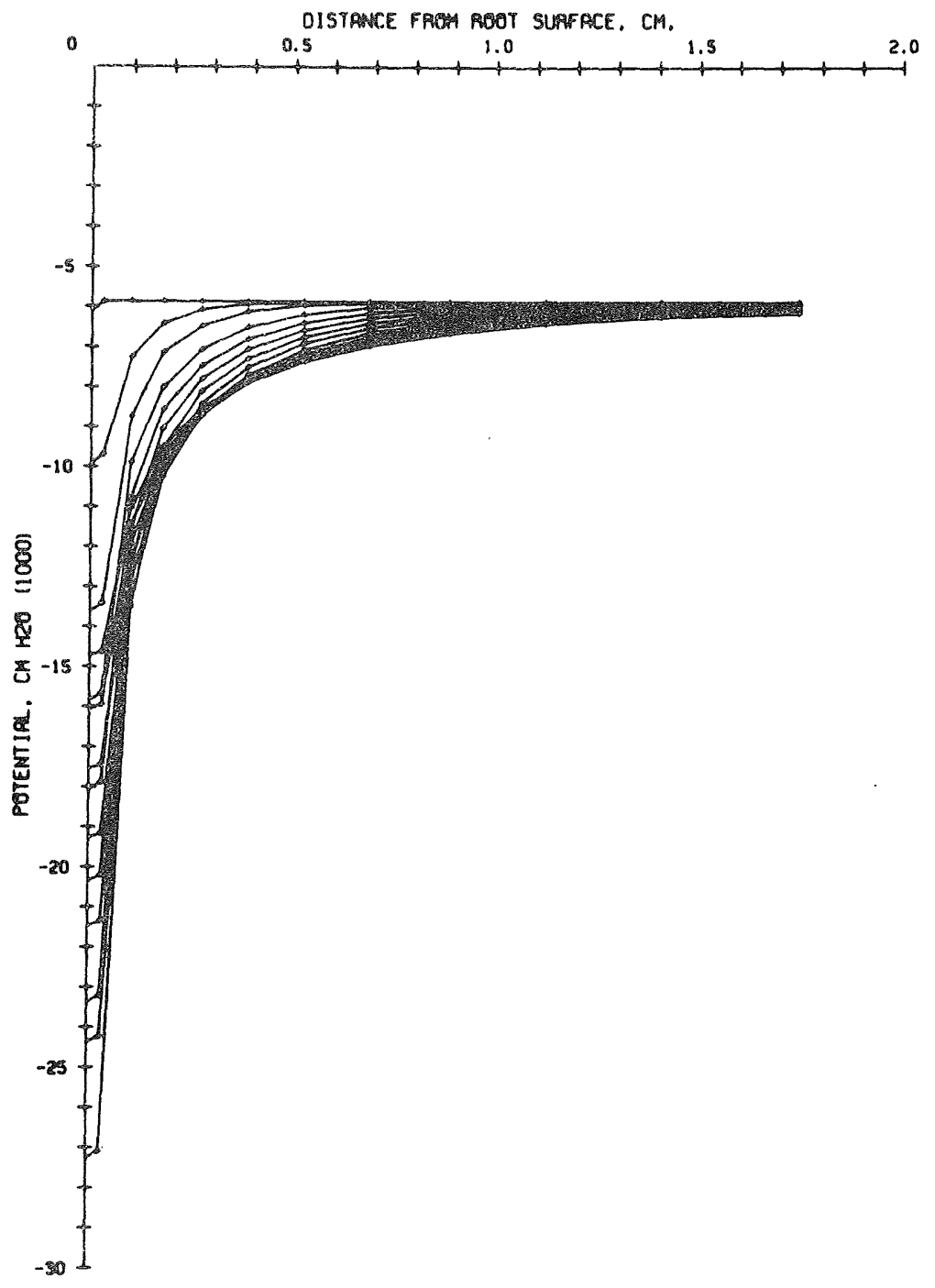

Fig. 8. Water potential distribution at $0,1,2,4,6,8,10,12,14,16,18,20,22$, and 24 hours, beginning at -5.76 bar initial condition

In Fig. 10 the size of the cone of water potential depression is represented as it developed in time from the six initial soil moisture contents. Size is defined as the distance from the cylinder axis to the point in the soil that has a potential level which is $95 \%$ of 
the potential difference between the inner and outer soil peels above the potential of the inner peel. From this figure it can be seen that except for the wetter soils, the radius of the cone is mainly determined by time and not by the initial conditions. In the initially dry

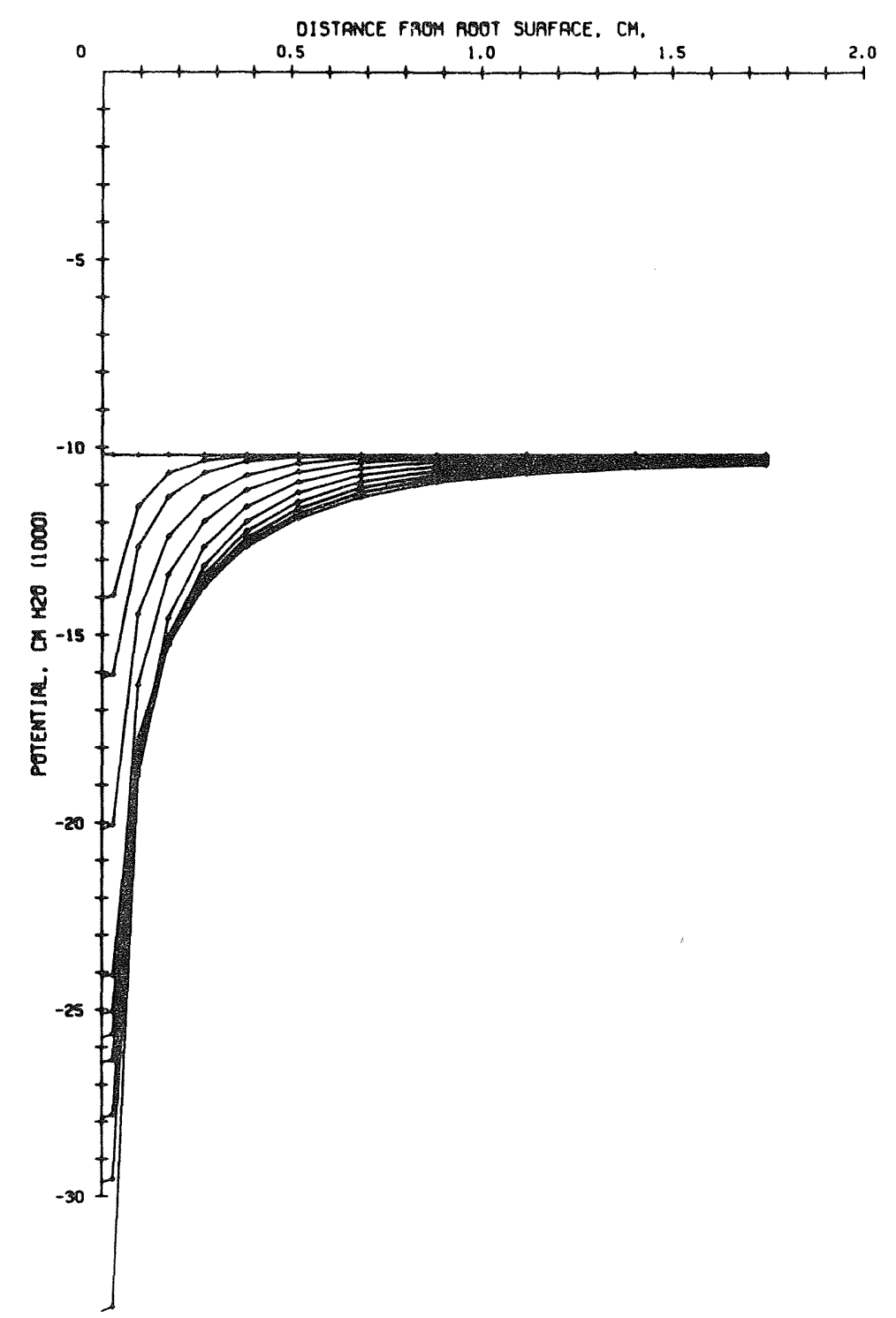

Fig. 9. Water potential distribution at $0,1,2,4,6,8,10,12,14,16$, and 18 hours, beginning at -10.0 bar initial condition

soils and early in the initially wet soils no water was extracted from the outer peel; so the size of the cone was not influenced by the cylinder wall restriction of no flow. However, after some time under the wetter conditions, the cylinder wall did begin to 
influence the profile. The filled points of Fig. 10 represent conditions where the water potential of the outer layer was decreased by more than $5 \%$ of the initial value.

The line in Fig. 10 connecting the points of $95 \%$ difference after 24 hours is very irregular and demonstrates the difficulty that would be experienced in predicting the potential profile after some time from a non-dynamic system approach. Effects of cylinder size, plant behavior and non-linear soil characteristics form a system too complex to oversee.

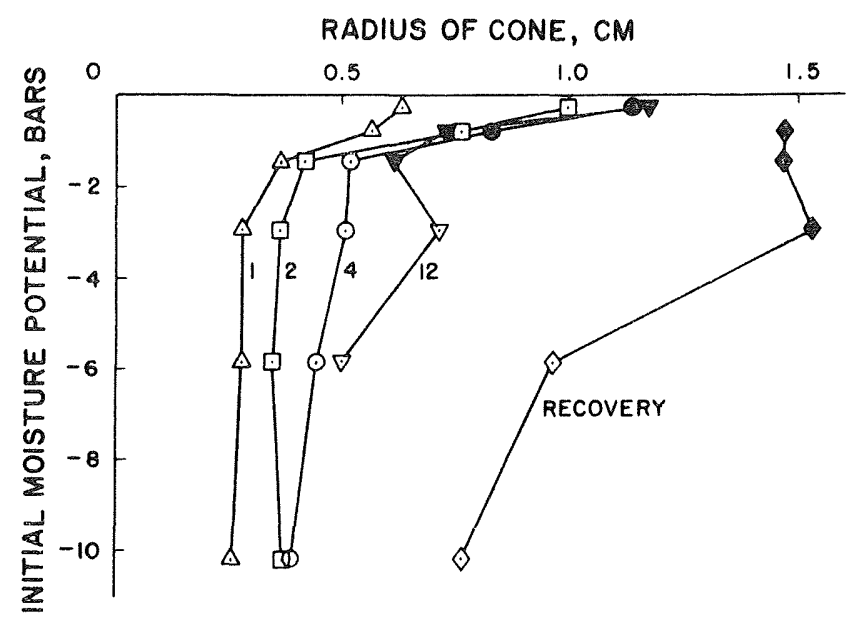

Fig. 10. Radius of cone within which $95 \%$ of potential difference between inner and outer soil peels is dissipated, with time in hours as the curve parameter

\section{Plant Water Potentials}

The course of plant water potential was very strongly dependent on both the environment and the initial soil moisture conditions. As can be seen by comparing the minimum root and leaf water potentials of Table 1 , only very small potential differences across the dry plant occurred even under a high sun, reflecting the relatively low. transpiration, and thus stem stream, rate. At higher transpiration rates from wetter soil significant potential differences did occur, but comparatively they are still very small.

Recovery root and leaf water potentials, at the end of the dark period, were nearly equal for all soil moisture conditions since little water movement through the plant was occurring. Although the aerial environment was being held completely steady, the plant exhibited a second-order response, indicated in Fig. 11 by the oscillation of root water potential. Thus in Table 1 the leaf water potential is in two cases higher than the root water potential at the end of the dark period. Although not indicated here, within a few minutes preceding this time, the other two of the four wetter regimes yielded similar backward potential differences. This cycling of potentials, indicating a tendency for surging back and forth in the plant, should not seem strange since cycling of transpiration rates has been reported several times, e.g., BOX (1965) and HOPMANS (1969), although a slight 


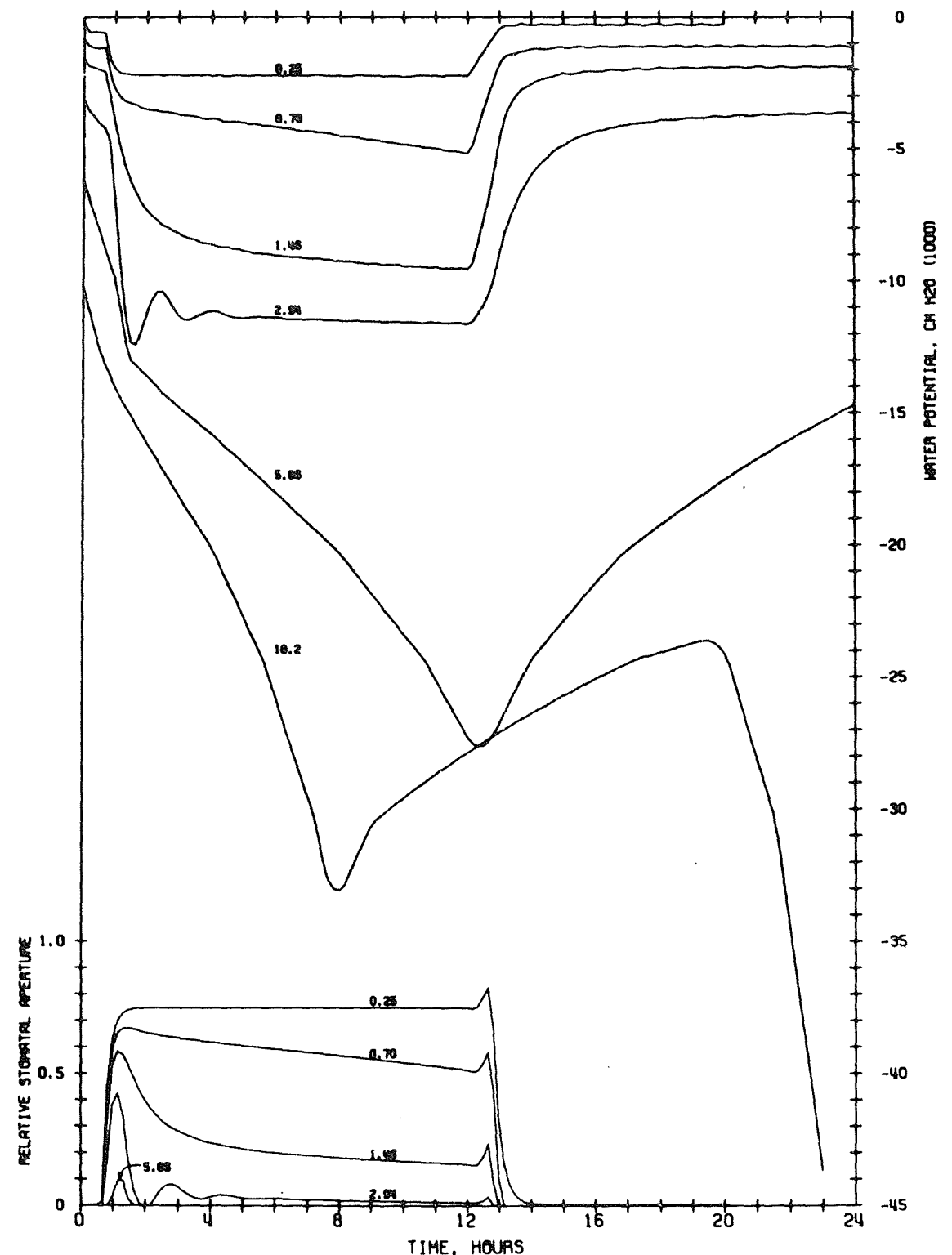

Fig. 11. Course of root water potential and relative stomatal aperture throughout the simulated 24 hours as function of initial water potential of the system

tendency for instability in the program may have accounted for at least some of the fluctuations seen here.

At zero simulation time the stomates were closed. Thus after an initial decrease in root water potential due to the cuticular transpiration, the wetter regimes resulted in a relatively constant root water potential (Fig. 11). As soon as the stomates opened the root 
water potential began to fall much faster, reflecting the increased transpiration rate. At lower soil moisture conditions this steepening of the curve was less pronounced since the stomatal aperture was smaller and under the driest regime, did not occur at all.

The subsequent daylight course of the root water potential depended very strongly on the soil moisture level. Sufficiently high conductivities were present in the wettest regime to allow a stable and high potential to be maintained. In the -0.77 -bar soil the root water potential continued to fall throughout the day reflecting the lower conductivities and still relatively open stomates, A similar response occurred under the -1.46 -bar regime but with the straight portion of the curve flatter, indicating the lower transpiration rate effected by the less-open stomates.

In the -2.89 -bar situation a rather violent reaction occurred due to the initial overshoot of transpiration rate beyond that which the system could support as evidenced by the larger-scaled cycling.

The root water potential continued to fall rather drastically throughout the day in the two driest soils even though the stomates remained closed except for a very brief and small opening in the one case. Soil conductivities were much lower and the rate of water movement to the root did not keep pace with even the cuticular transpiration rate.

As soon as the simulated sun started to set, the entire system began to respond very rapidly and by sundown the root water potential in the wetter regimes had nearly returned to its final recovery value. In the progressively drier situations the effect of lower soil conductivities is apparent in the progressively slower response to the reduced transpiration load. A complete night period of eleven hours was insufficient time for the root water potential even to approach the eventual equilibrium value.

In both of the two driest situations the root water potential continued to fall for several minutes after the sun started down. Thus although the sun had been caused to begin to set at a root water potential of -30 bars the root water potential of the driest plant fell to -32.5 bars before finally beginning to rise. After eleven hours of darkness the sun came up and the root water potential fell very drastically. The abrupt changes in slope of the two driest recovery curves are due to the linear interpolation used in the root water potential versus water content relationship.

\section{Stomatal Action}

A first-order exponential delay with a time constant of 15 minutes caused the delay in initial opening of the stomates (Fig. 11). Very quickly the stomates opened rather widely, in some cases to an even larger aperture than could be supported by the system. When the system could support the large aperture, as in the wettest situation, the aperture remained essentially constant. In the -0.77 -bar case, slow plant dehydration caused a slow closing movement of the stomates. The finally constant rate of fall of the -1.44-bar curve appeared later since the complete system was slower to arrive at a relatively constantly moving situation.

The overshoot of stomatal aperture beyond that which the -2.89 -bar regime could support caused a rather rapid plant dehydration and a subsequent closure of the stomates, A quick recovery allowed the stomates to reopen and some overshoot again occurred. Subsequent cycling soon damped out and the stomates remained slightly open for the remainder of the day.

After an initial slight opening in the -5.76 -bar situation the stomates closed tightly 
and remained so throughout the day. The stomates in the driest condition did not open at all.

At the end of the high sun period, the reduced transpiration load resulted in sufficient rehydration to cause a brief period of increased stomatal aperture, even in the reduced light, in those stomates already open. The reduced light intensity and subsequent increase of $\mathrm{CO}_{2}$ in the leaves soon overruled the increased hydration however and the stomates closed.

\section{Discussion and Evaluation of the Model}

The model combines bits and pieces of knowledge of physics of transport processes, plant physiology, and soil physics in such a way that the dynamic response of a simplified but complete soil-plant-atmosphere system results. No response predicted by the model seems unreasonable although absoluteness of the quantitative results is not claimed. Far too many physical and biological parameters and relationships are estimated for the model to simulate nature accurately. Many weaknesses of the model may be removed by applying better and/or new data concerning many of the relationships and parameters. Since the language CSMP is used, changes to reflect increased knowledge of certain parts of the system can be made relatively easily.

The water potential profiles as given in Figs. 4 through 9 are the results predicted for a non-growing plant with one straight root. Profiles about growing roots will be different but large changes are not to be expected, because growth and aging are relatively slow processes compared with the time required for the development of such profiles. Longerterm models must include growth and aging of the root system, In field crop models rooting density must be taken into account, which will cause not only horizontal but also vertical gradients in the soil.

Much more progress with comparably less effort can be made in studying complex systems of non-linear components using the proper simulation language. Troika illustrates this.

Models of this type are useful in determining the relative importance of parameters and relationships via sensitivity tests. They also yield results pertinent to designing experiments to measure important variables or constants, and to plan breeding directions.

Integration, interpolation, and simplifications of the results of this type of model should also yield more rational approaches to engineering-type plant-water relations for use in water management practice.

Much work remains to be done with this and successive models. Sensitivity tests of the importance of such parameters as root resistance as affected by age of the root, temperature, water potential, etc.; stomatal resistance as affected by $\mathrm{CO}_{2}$, light, water levels, etc.; stem resistance; rooting density; soil characteristics; aerial environment; and several other factors should yield insight into their importance in the dynamic system.

\section{Acknowledgement}

The work reported here was done while the senior author was on sabbatical leave from Clemson University in the laboratory of Professor C. T. DE WIT at Wageningen, the Netherlands. Appreciation is expressed to Professor DE WIT and his staff for the assistance, advice, and inspiration received. The International Agricultural Center provided support for living expenses in Wageningen, which is appreciated.

This Technical Contribution No. 890 of the South Carolina Experiment Station is published by permission of the Director. 


\section{References}

Box, E. F.: Cyclic changes in transpiration of sunflower in a steady environment. J. Exp. Bot. 19 (58), 167-175 (1968).

BrenNAN, R. D., WIT, C. T. DE, WILliams, W. A., QuATTRIN, E. V.: The utility of a digital simulation language for ecological modeling. Oecologia 4, 113-132 (1970).

Cowan, I. R.: Transport of water in the soil-plant-atmosphere system; J. Appl. Ecol. 2, 221-239 (1965).

CowAN, I. R., MILTHORPE, F. L.: Plant factors influencing the water status of plant tissues. In: Water Deficits and Plant Growth. Ed.: T. T. Kozlowski. New York: Academic Press 1968, Ch. 6.

GARDNER, W. R.: Dynamic aspects of water availability to plants. Soil Sci. 89, 63-73 (1960).

GARDNER, W. R.: Dynamic aspects of soil water availability to plants. Ann. Rev. Plant Physiol. 16, 323-342 (1965).

HANKS, R. J., BOWERS, S. A.: Numerical solution of the moisture flow equations for infiltration into layered soils. Soil Sci. Soc. Amer. Proc. 26, 530-534 (1962).

Hopmans, P. A. M.: Types of stomatal cycling and their water relations in bean leaves. Pflanzenphysiol. 60 (3), 242-254 (1969).

IBM: System/360 Continuous System Modeling Program (360A-CX-16X) Users Manual 1968.

Keulen, H. van, Beek, C. G. E. M. van: Water transport in layered soils. Neth.J. Agr. Sci. 19, 138-153 (1971).

Klute, A., PETERS, D. B.: Water uptake and root growth. In: Root Growth, pp. 105-133. Ed.: W. J. WHITTINGTON. London: Butterworths 1969.

Lambert, J. R., Penning de VRIES, F. W. T.: The model Troika: listing. Clemson, South Carolina: Clemson University, Agr. Engr. Res. Rep. No. 16, (1971).

PENNING DE VRIES, F. W. T.: A model for simulating transpiration of leaves, with special attention to stomatal functioning. J. Appl. Ecol. 9, 57-77 (1972).

PHILIP, J. R.: The physical principles of soil water movement during the irrigation cycle. Trans. 3rd Congr. Intern. Comm. Irrig. Drainage, 8, 125 (1957).

SHIH, Sun-Fu: A mathematical solution for transient radial flow in unsaturated soil. Unpublished Ph. D. Thesis. Raleigh: N. C. State University 1969.

SINGH, R., FRANZINI, J. B.: Unsteady flow in unsaturated soils from a cylindrical source of finite radius. J. Geophys. Res. 72 (4), 1207-1215 (1967).

SLATYER, R. O.: Plant-water relationships. New York: Academic Press 1967. 